\title{
EKSPLORASI SPESIES TUMBUHAN BERKHASIAT OBAT BERBASIS PENGETAHUAN LOKAL DI KABUPATEN PIDIE
}

\author{
Exploration of Medicinal Plant Species Based on Local Wisdom \\ from Pidie District
}

\author{
Saudah 1), Vera Viena 2), Ernilasari 3), \\ 1,3 Universitas Syiah Kuala/MIPA Biologi, Banda Aceh, Indonesia \\ 2,3 Universitas Serambi Mekkah/Teknik Lingkungan, Banda Aceh, Indonesia \\ *e-mail: saudah@serambimekkah.ac.id
}

\begin{abstract}
Presently the community tends to avoid the use of modern medicine and turn to nature (back to nature) with traditional medicine using medicinal plants. The exploration of medicinal plant used in traditional medicine in Pidie District aims to explore the potential of plant species used, record the plant parts used, how to process and to use the plants and how to obtain them from the nature habitat. The method used for data collection was exploratory surveys and Participatory Rural Appraisal (PRA) methods. The data obtained were analyzed descriptively and showed in the form of tables and figures. The results of the study found 106 types of plants used in traditional medicine that were spread into 67 plant families. The most widely used of medicinal plant species were from the Zingiberaceae family. The most widely used plant part is the leaf part. The method of medicinal processing is done by boiling (decoction), the results of the ingredients are used as oral administration by drinks. Generally, the plants used for medicine by the people of Pidie Distric are wild plants, and 68\% of which grow from home gardens and fields.
\end{abstract}

Keywords: exploration, traditional medicinal plants, local knowledge, Pidie Distric

\begin{abstract}
ABSTRAK
Kecenderungan masyarakat saat ini mulai menolak penggunaan obat moderen dan beralih ke alam (back to nature) dengan pengobatan tradisional menggunakan tumbuhan obat. Eksplorasi jenis tumbuhan obat yang digunakan dalam pengobatan tradisonal di Kabupaten Pidie bertujuan untuk menggali potensi jenis tumbuhan yang digunakan, mendata bagian yang digunakan, cara pengolahan dan penggunaan tumbuhan serta cara mendapatkannya dari alam. Metode yang dilakukan dalam pengumpulan data adalah survei eksploratif dan Participatory Rural Appraisal (PRA). Data yang diperoleh dianalisis secara deskriptif dan ditampilkan dalam bentuk tabel dan gambar. Hasil penelitian didapatkan 106 spesies tumbuhan obat yang digunakan dalam pengobatan tradisional yang berasal dari 67 famili. Spesies tumbuhan obat yang paling banyak digunakan di wilayah Pidie berasal dari famili Zingiberaceae. Bagian tumbuhan obat yang paling banyak digunakan adalah bagian daun. Cara pengolahan tumbuhan obat secara umum dilakukan dengan perebusan, hasil ramuan digunakan dalam bentuk minuman. Secara umum tumbuhan yang digunakan untuk obat oleh masyarakat Kabupaten Pidie adalah jenis tumbuhan liar, dan sebanyak 68\% tumbuh dari pekarangan rumah maupun kebun atau ladang.
\end{abstract}

Kata kunci: eksplorasi, tumbuhan obat tradisional, pengetahuan lokal, Kabupaten Pidie

\section{PENDAHULUAN}

Penduduk Indonesia mempunyai adat istiadat dan budaya yang sangat beragam. Keanekaragaman etnik menyebabkan masyarakat masih menggunakan tumbuhan sebagai obat alami, terutama masyarakat yang tinggal di pedesaan. Pengetahuan pemanfaatan tumbuhan obat diwariskan secara turun temurun (Murni dkk., 2012). Seiring dengan perkembangan waktu, 
kemajuan ilmu pengetahuan dan ilmu teknologi, telah meningkatkan penggunaan tumbuhan obat (Sampurno, 2007). Kecenderungan masyarakat akan kebosanan penggunaan obat moderen dan beralih ke alam (back to nature) dengan pengobatan tradisional menggunakan tumbuhan obat (Pramesti dkk., 2012).

Penelitian tentang pengetahuan dan pemanfaatan tumbuhan obat oleh masyarakat lokal telah banyak dilakukan di Indonesia, diantaranya pemanfaatan famili Zingiberaceae sebagai obat tradisional oleh masyarakat di Kotamadya Banjarbaru. Dari hasil penelitian tersebut diketahui jenis-jenis tanaman yang dimanfaatkan sebagai obat yaitu : Alpinia galanga, Curcuma longa $\mathrm{L}$ atau C. domestica Val., C. zanthorrhiza Roxb., C. aeruginosa, Kaempferia galanga L, K. pandurata Roxb., Zingiber officinale Rosc. Etnis yang menggunakan jenis-jenis dari famili Zingiberaceae diantaranya adalah etnik Banjar (61\%), etnik Jawa (23\%) dan etnis lain 15\% (gabungan dari etnik Madura, Batak, Dayak, Bugis, Sunda dan sebagian kecil Cina)( Kuntorini, 2005).

Selain itu, penelitian tentang identifikasi dan pemanfaatan tumbuhan obat Suku Dani di Kabupaten Jayawijaya Papua, ditemukan 16 spesies tumbuhan obat dari 12 famili yang dimanfaatkan oleh masyarakat dengan khasiat dan penggunaan yang berbeda-beda dan sederhana (Mabel et al., 2016). Selanjutnya, etnobotani medis masyarakat kemukuman Pulo Breueh Selatan ditemukan 67 spesies tumbuhan obat. Bagian tumbuhan yang digunakan sebagai obat adalah, daun, buah, getah, batang, kulit, rimpang, dan umbi. Jenis penyakit yang diobati dengan menggunakan tumbuhan obat beragam yaitu sebanyak 5 jenis penyakit. (Wardiah dkk, 2016).

Potensi tumbuhan sebagai obat tradisional terdapat di berbagai daerah. Setiap daerah memiliki sistem pemanfaatan tumbuhan obat yang bersifat khas dan berbeda dengan daerah lain. Hingga saat ini pengetahuan lokal masyarakat tentang tumbuhan obat di Kecamatan Tangse, Kabupaten Pidie belum terdokumentasi dan eksplorasi jenis tumbuhan yang digunakan belum terdata dengan secara ilmiah. Oleh karenanya, maka perlu dilakukan penelitian tentang eksplorasi jenis tumbuhan obat yang digunakan oleh masyarakat Kabupaten Pidie berdasarkan pengetahuan lokal. Tujuan dari penelitian ini adalah, menggali potensi jenis tumbuhan yang digunakan dalam pengobatan tradisional, mendata bagian yang digunakan, cara pengolahan dan penggunaan tumbuhan serta cara mendapatkannya.

\section{METODE}

\section{Tempat dan Waktu}

Penelitian ini dilakukan di Kabupaten Pidie pada bulan Maret 2018.

\section{Bahan dan Alat}

Bahan dan alat yang digunakan dalam penelitian ini antara lain: jenis-jenis tumbuhan obat, alkohol 70\%, peta lokasi penelitian, daftar pertanyaan (kuesioner), literatur sebagai bahan pendukung pustaka, alat perekam suara, kamera, GPS (global positioning system), alat tulis dan buku lapangan, serta perlengkapan herbarium.

\section{Metode Penelitian}

Metode yang dilakukan dalam pengambilan data adalah survei eksploratif dan metode Participatory Rural Appraisal (PRA), yaitu proses pengkajian yang berorientasi pada keterlibatan dan peran masyarakat secara aktif responden dalam penelitian (Martin, 1995 dalam Nasution, 2009). Pemilihan kecamatan dan perkampungan dilakukan secara purposive sampling. Penelitian dilakukan dengan dua pendekatan, yaitu penelitian lapangan untuk mendapatkan data primer dan kemudian diperkaya dengan data sekunder. Pengumpulan data primer dilakukan dengan 
melibatkan masyarakat lokal dan anggota masyarakat yang memiliki keahlian dan status sosial seperti kepala desa, tua-tua adat dan anggota masyarakat. Kriteria pemilihan berdasarkan pada kemampuan dan praktek pengobatan tradisional yang dilakukan informan.

\section{Teknik Pengumpulan Data}

Pengumpulan data primer diperoleh dengan keterlibatan masyarakat diperoleh melalui wawancara dengan teknik wawancara semi struktural yang berpedoman pada daftar pertanyaan (kuesioner) yang mencakup, nama lokal tumbuhan, bagian yang digunakan, manfaat tumbuhan , status tumbuhan (liar atau budidaya) dan cara penggunaannya (Susiarti, 2015). Setiap tumbuhan yang digunakan sebagai bahan obat tradisional di foto dan diambil contohnya untuk dikoleksi yang selanjutnya dibuat herbarium untuk dilakukan identifikasi. Jika ditemukan jenis tumbuhan yang tidak dapat diidentifikasi maka jenis tumbuhan tersebut dikirim ke Laboratorium Botani Universitas Syiah Kuala Banda Aceh.

\section{Analisis Data}

Data primer yang diperoleh dari hasil wawancara dengan informan ditabulasi kemudian dianalisis degan menggunakan cara deskriptif dan disajikan dalam bentuk tabel dan grafik.

\section{HASIL DAN PEMBAHASAN}

Jenis tumbuhan yang digunakan dalam pengobatan tradisional di Kecamatan Tangse, Kabupaten Pidie sebanyak 106 jenis yang tersebar dalam 67 suku (Tabel 1) Diantara 106 jenis tumbuhan tersebut terdapat 7 jenis yang belum diketahui nama ilmiahnya, dalam penggunaannya jenis ini sangat sedikit digunakan dan pengetahuan masyarakat tentang tumbuhan tersebut juga sangat rendah. Jenis-jenis tumbuhan yang paling banyak digunakan dalam pengobatan adalah berasal dari famili Zingiberaceae (8 jenis), kemudian berturut-turut Asteraceae (6 jenis), Piperaceae ( 5 jenis), Fabaceae ( 4 jenis) dan selebihnya kurang dari 3 jenis, bahkan hanya diwakili oleh satu jenis. Zingiberaceae dalam kehidupan sehari-hari selain digunakan untuk obat juga digunakan untuk bumbu masak. Senyawa kimia yang terkandung dalam Zingiberaceae dapat dimanfaatkan sebagai antiokasidan (Praptiwi dkk, 2015). Kandungan minyak atsiri pada famili Zingiberaceae berpotensi untuk dikembangkan sebagai bahan obat yang mempunyai nilai ekonomi yang tinggi (Ma'mun, 2006).

\section{a. Bagian Tumbuhan yang Digunakan}

Bagian tumbuhan yang sering digunakan sebagai obat adalah akar, rimpang, umbi, batang, kulit batang, daun, biji, buah, kulit buah dan semua bagian (Gambar 1).

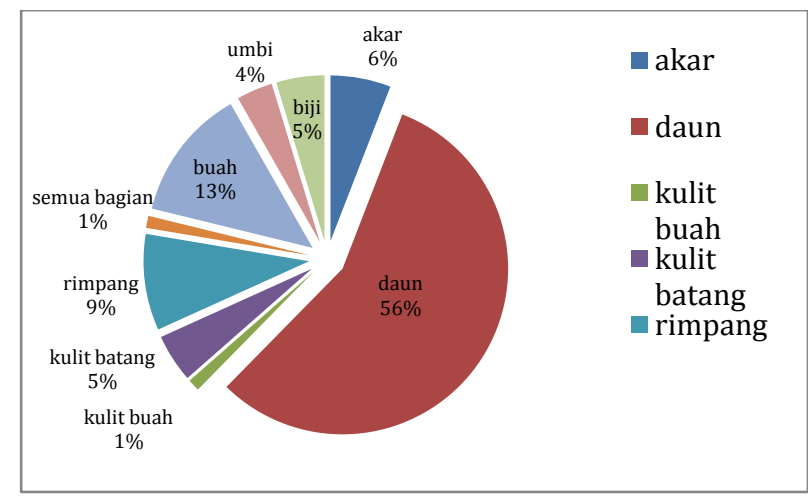

Gambar 1. Bagian tumbuhan yang digunakan dalam ramuan obat 
Daun merupakan organ yang paling banyak digunakan dalam pengobatan tradisional di Kabupaten Pidie, Aceh (56\%). Hal ini dikarenakan, daun merupakan organ yang paling mudah diperoleh karena jumlahnya yang banyak. Simplisia daun merupakan jenis simplisia yang paling banyak digunakan juga dikarenakan daun adalah organ tanaman yang paling mudah dikenali, diambil dan dimanfaatkan. Daun dapat dipanen setiap saat tanpa bergantung terhadap musim dan paling mudah untuk diolah atau diramu sebagai bahan ramuan atau jamu (Widiyastuti dkk., 2018).

Daun juga mengandung senyawa seperti tanin, alkaloid minyak atsiri yang berguna sebagai obat yang tersimpan di jaringan pada daun. Selain itu tekstur daun yang lembut sangat mudah untuk diolah dibandingkan dengan bagian lainnya. Berdasarkan hasil wawancara dengan responden, spesies Anredera cordifolia merupakan spesies yang sering digunakan oleh masyarakat dalam mengobati penyakit, baik ringan maupun berat.

\section{b. Cara pengolahan ramuan}

Penggunaan tumbuhan untuk pengobatan oleh masyarakat di Kabupaten Pidie lebih banyak dilakukan dalam bentuk campuran berbagai tumbuhan dan sangat sedikit yang menggunakan tumbuhan secara tunggal. Penggunaan tumbuhan secara tunggal umumnya dilakukan untuk mengobati penyakit ringan, seperti luka ringan, penyakit kulit, sariawan, pusing dan sakit kepala. Selanjutnya, penggunaan tumbuhan dalam bentuk campuran atau ramuan banyak digunakan untuk mengobati penyakit kolesterol, diabetes melitus, darah tinggi, asam urat, pengobatan pasca melahirkan dan sebagainya. Masyarakat Kabupaten Pidie percaya bahwa pencampuran bahanbahan tumbuhan sebagai obat dapat memberikan khasiat yang tepat terhadap suatu penyakit. Dalam hal penggunaan ramuan, contoh sederhana adalah ramuan Jawa kunyit asam yaitu rimpang kunyit dalam penggunaan sebagai bahan obat harus dicampur dengan asam. Hal ini dikarenakan zat aktif yang ada di dalam kunyit akan stabil bila terdapat dalam lingkungan asam (Limanantik \& Atik, 2003).

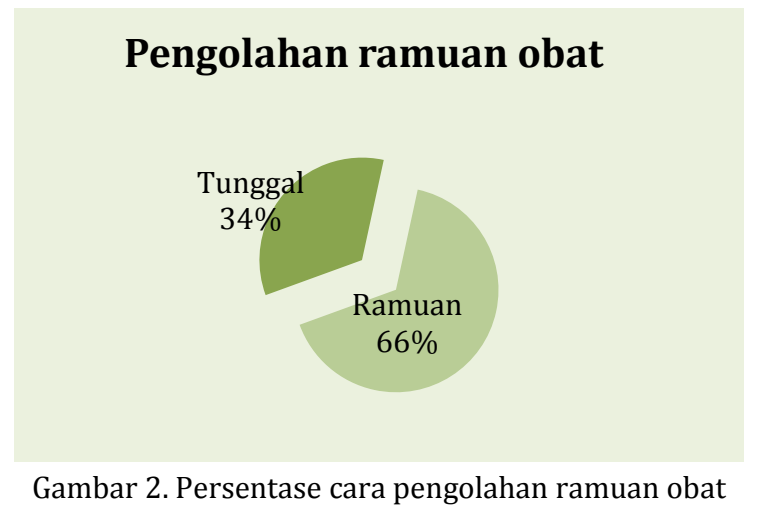

Pengolahan tumbuhan obat dilakukan dengan cara diremas, ditumbuk, digiling, ditempel dan direbus. Cara pengolahan yang paling banyak dilakukan oleh masyarakat adalah dengan cara direbus. Pengolahan dengan cara direbus tergolong sangat mudah dan hemat karena dapat dilakukan berulang kali. Ramuan yang dihasilkan dari rebusan selalu segar dan bisa dikonsumsi langsung. Pada masyarakat desa Pangandaran pengolahan tumbuhan sebagai obat lebih sering dilakukan dengan cara merebus bagian tumbuhan yang segar maupun kering hingga zat-zat aktif dari tumbuhan terlarut pada air rebusan (Asep dkk., 2016). 


\section{c. Cara penggunaan}

Penggunaan ramuan oleh masyarakat di Kabupaten Pidie terbagi menjadi dua cara utama yaitu secara oral (pemakaian dalam) dan topical (pemakaian luar). Keseluruhan cara penggunaan ramuan sebagai berikut: diminum $(39,40 \%)$, ditempel $(21,70 \%)$, dioles $(17,00 \%)$, dimakan $(11,56 \%)$ dan ditetes $(10,20 \%)$. Penggunaan dengan cara diminum diyakini masyarakat lebih mudah, lebih mujarab dan penyakit yang mereka rasakan akan segera sembuh karena reaksi dari obat lebih cepat. Masyarakat percaya bahwa dengan cara diminum akan mempercepat reaksi penyembuhan dibandingkan dengan dioles, ditetes, ditempel dan dimakan langsung. Sejalan dengan penelitian ini, penggunaan ramuan pada masyarakat Suku Dayak di Desa Kayu Tanam Kabupaten Landak, Kalimantan yang paling banyak adalah dengan cara diminum yaitu sebanyak 31 jenis tumbuhan obat (Efrimila dkk. 2015).

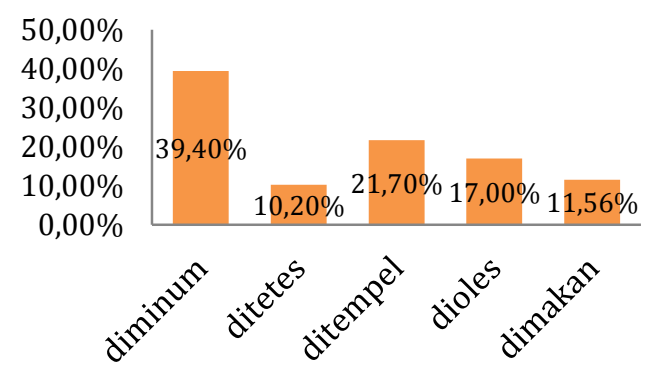

Gambar 3. Persentase cara pengolahan ramuan obat

\section{d. Habitus Tumbuhan Obat}

Umumnya jenis tumbuhan yang digunakan oleh masyarakat sebagai obat di Kabupaten Pidie merupakan tumbuhan yang berasal dari tanaman hias, bahan pelengkap masakan, sayuran, buah-buahan dan tumbuhan liar. Tumbuhan tersebut diperoleh dari sekitar tempat tinggal mereka seperti pinggir jalan, pekarangan rumah, kebun dan hutan, sebagian lainnya juga mereka peroleh dari membeli di pasar (Gambar 4). Umumnya tumbuhan yang digunakan adalah jenis tumbuhan liar sebanyak 68\%. Tumbuhan liar yang dimanfaatkan sebagai bahan ramuan dapat diperoleh dari pekarangan rumah, kebun maupun ladang.
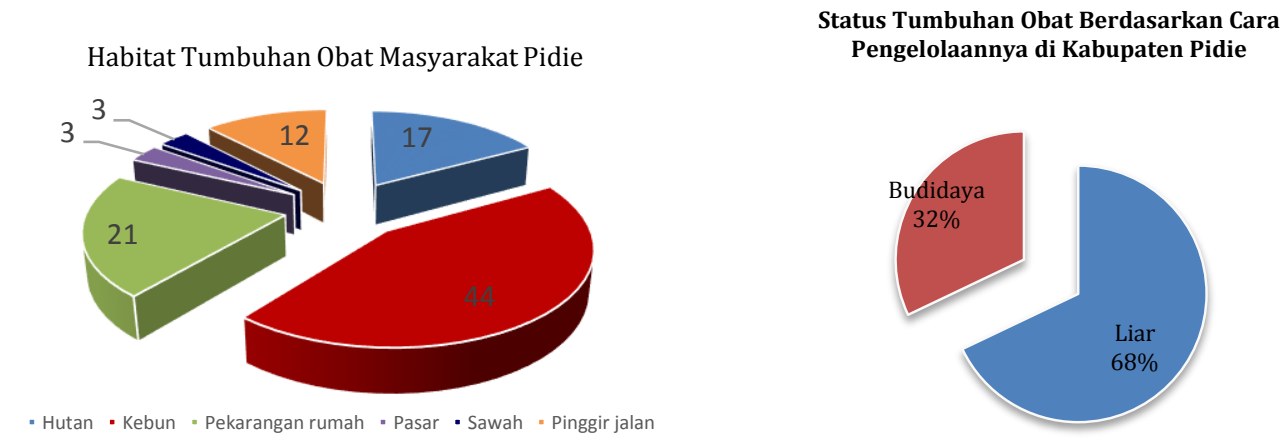

Gambar 4. Status dan habitat tumbuhan obat di Kabupaten Pidie

Berdasarkan status, tumbuhan dikelompokkan menjadi dua yaitu tumbuhan liar dan tumbuhan budidaya. Tumbuhan liar merupakan kelompok tumbuhan yang pertumbuhannya cepat sehingga menggangu habitat tumbuan lain (Febrisari dkk, 2008). Menurut Astutik et.al 
(2019) sistem pengelolaan hutan untuk budidaya tanaman obat yang berkelanjutan sangat diperlukan karena sebagian besar tanaman obat saat ini masih mengandalkan panenan dari tumbuhan liar. Masyarakat Pidie masih mengandalkan sebagian perolehan bahan ramuan dari tumbuhan liar yaitu dengan proporsi $68 \%$. Kondisi ini tentunya tidak menjamin keberlangsungan praktek pengobatan karena pemanenan terus menerus dari alam akan mengancam kelestarian spesies tumbuhan obat. Untuk itu perlu dilakukan upaya konservasi dan mengenalkan konsep pemanenan berkelanjutan terhadap masyarakat di Pidie. Konservasi tumbuhan dapat dilakukan secara in situ di dalam kawasan tempat tumbuh atau secara ex situ di luar habitat tumbuhan (Noorhidayah dkk, 2006). Mendorong masyarakat Pidie untuk mau menanam tumbuhan obat di sekitar pekarangan termasuk dalam upaya konservasi ex situ yang dapat menjaga ketersediaan dalam jangka panjang.

\section{KESIMPULAN}

Terdapat 106 jenis yang tersebar dalam 67 famili tumbuhan obat yang digunakan dalam pengobatan tradisional di Kabupaten Pidie. Jenis tumbuhan banyak digunakan adalah dari famili Zingiberaceae. Bagian tumbuhan yang paling banyak digunakan adalah daun. Pengolahan ramuan dilakukan dengan perebusan, hasil ramuan obat dikonsumsi dalam bentuk minuman. Sebanyak $68 \%$ tumbuhan yang digunakan untuk obat oleh masyarakat Kabupaten Pidie adalah jenis tumbuhan liar yang tumbuh dari pekarangan rumah maupun kebun atau ladang.

\section{Lampiran}

Tabel 1. Jenis tumbuhan yang digunakan oleh masyarakat Kabupaten Pidie

\begin{tabular}{|c|c|c|c|c|c|}
\hline No & Familia & Nama Ilmiah & Nama daerah & $\begin{array}{l}\text { Bagian } \\
\text { digunakan }\end{array}$ & Kegunaan \\
\hline \multirow[t]{4}{*}{1} & Acanthaceae & $\begin{array}{l}\text { Andrographis paniculata } \\
\text { Ness. }\end{array}$ & Sambiloto & Daun & Obat malaria \\
\hline & & Clinacanthus nutans L. & Belalai gajah & Daun & Obat amandel \\
\hline & & $\begin{array}{l}\text { Graptophyllum pictum } \\
\text { (L.) Griff. }\end{array}$ & Puding & Daun & $\begin{array}{l}\text { Campuran } \\
\text { ramuan/pendarahan } \\
\text { pasca melahirkan }\end{array}$ \\
\hline & & $\begin{array}{l}\text { Strobilanthes crispa } \\
\text { Blume }\end{array}$ & Kejibeling & Daun & $\begin{array}{l}\text { Sakit pinggang, } \\
\text { kencing batu }\end{array}$ \\
\hline 2 & Agavaceae & Cordyline fruticosa L. & Daun andong & Daun & $\begin{array}{l}\text { Batuk berdarah, } \\
\text { disentri dan wasir }\end{array}$ \\
\hline 3 & Alliaceae & Allium sativum $\mathrm{L}$. & Bawang putih & Umbi & $\begin{array}{l}\text { Penyakit jantung, } \\
\text { kolesterol, dan gigitan } \\
\text { serangga }\end{array}$ \\
\hline 4 & Amaranthaceae & $\begin{array}{l}\text { Aerva lanata (L.) Juss ex } \\
\text { Schult }\end{array}$ & $\begin{array}{l}\text { On manek } \\
\text { mano }\end{array}$ & Daun & $\begin{array}{l}\text { Antidiabetes, ramuan } \\
\text { pasca melahirkan }\end{array}$ \\
\hline 5 & Amaryllidaceae & Allium cepa L. & Bawang merah & Umbi lapis & Masuk angin \\
\hline 6 & Anarcadiaceae & $\begin{array}{l}\text { Lannea coromandelica } \\
\text { (Houtt.) Merr. }\end{array}$ & On keurundong & Daun & Campuran ramuan 44 \\
\hline 7 & Annonaceae & Annona muricata L. & Sirsak & $\begin{array}{l}\text { Daun dan } \\
\text { buah }\end{array}$ & Anti kanker \\
\hline 8 & Apiaceae & Feoniculum vulgare L. & Jira maneh & Biji & $\begin{array}{l}\text { Obat sakit kepala, } \\
\text { campuran ramuan } 44\end{array}$ \\
\hline
\end{tabular}




\begin{tabular}{|c|c|c|c|c|c|}
\hline No & Familia & Nama Ilmiah & Nama daerah & $\begin{array}{l}\text { Bagian } \\
\text { digunakan }\end{array}$ & Kegunaan \\
\hline & & Cuminum cyminum L. & Jira ungkot & Biji & $\begin{array}{l}\text { Sakit kepala, ramuan } \\
\text { pasca melahirkan, } \\
\text { campuran ramuan } 44\end{array}$ \\
\hline & & Apium graveolens L. & On saop & Daun & Darah tinggi \\
\hline \multirow[t]{2}{*}{9} & Apocynaceae & $\begin{array}{l}\text { Calotropis gigantea (L.) } \\
\text { Dryand }\end{array}$ & Biduri & Getah & Kutil \\
\hline & & Alstonia scholaris R.Br. & Bak rubek & $\begin{array}{l}\text { Kulit } \\
\text { batang }\end{array}$ & $\begin{array}{l}\text { Malaria, sakit } \\
\text { tenggorokan }\end{array}$ \\
\hline 10 & Araceae & Colocasia esculenta L. & On lubueu & $\begin{array}{l}\text { Getah dan } \\
\text { kulit } \\
\text { pelepah }\end{array}$ & Luka sayat \\
\hline \multirow[t]{2}{*}{11} & Arecaceae & Cocos nucifera $\mathrm{L}$. & Kelapa & Buah & Demam, keracunan \\
\hline & & Areca catechu L. & Pinang & Buah & Penambah stamina \\
\hline \multirow[t]{6}{*}{12} & Asteraceae & Eclipta alba $\mathrm{L}$. & On sumpung & Daun & $\begin{array}{l}\text { Obat pasca } \\
\text { melahirkan, demam, } \\
\text { sakit kepala }\end{array}$ \\
\hline & & Blumea balsamifera $\mathrm{L}$. & On capa & Daun & $\begin{array}{l}\text { Diare, campuran } \\
\text { ramuan pasca } \\
\text { melahirkan, wasir, } \\
\text { sakit perut dan masuk } \\
\text { angin }\end{array}$ \\
\hline & & Gynura procumbens $\mathrm{L}$. & $\begin{array}{l}\text { On sambung } \\
\text { nyawa }\end{array}$ & Daun & $\begin{array}{l}\text { Antidiabetes, } \\
\text { kolesterol }\end{array}$ \\
\hline & & Elephantopus scaber $\mathrm{L}$. & Tutup bumo & Daun & $\begin{array}{l}\text { Campuran obat pasca } \\
\text { melahirkan, demam, } \\
\text { infulenza, bisul. }\end{array}$ \\
\hline & & Tagetes erecta $\mathrm{L}$. & Bak seurune & $\begin{array}{l}\text { Bunga dan } \\
\text { daun }\end{array}$ & Masuk angin \\
\hline & & $\begin{array}{l}\text { Vernonia amygdalina } \\
\text { Delile }\end{array}$ & Daun afrika & Daun & $\begin{array}{l}\text { Diabetes, darah tinggi, } \\
\text { mual, menambah } \\
\text { nafsu makan }\end{array}$ \\
\hline 13 & Basellaceae & $\begin{array}{l}\text { Anredera cordifolia } \\
\text { (Ten.) Steenis }\end{array}$ & On binahong & Daun & $\begin{array}{l}\text { Menyembuhkan luka, } \\
\text { asam urat, sakit } \\
\text { kepala, mimisan }\end{array}$ \\
\hline 14 & Bombaceae & Durio zibethinus L. & On drien & Daun & $\begin{array}{l}\text { Batuk berdarah, } \\
\text { disentri dan wasir, } \\
\text { malaria }\end{array}$ \\
\hline 15 & Brassicaceae & $\begin{array}{l}\text { Nasturtium } \\
\text { microphyllum Boenn. Ex } \\
\text { Rchb }\end{array}$ & Selada air & Daun & $\begin{array}{l}\text { Mencegah kanker dan } \\
\text { diabetes }\end{array}$ \\
\hline 16 & Caricaeae & Carica papaya L. & On peutek & $\begin{array}{l}\text { Daun, buah } \\
\text { dan biji }\end{array}$ & $\begin{array}{l}\text { Obat demam dan } \\
\text { malaria }\end{array}$ \\
\hline 17 & Clusiaceae & Garcinia mangostana L. & $\begin{array}{l}\text { Kulet boh } \\
\text { manggeh }\end{array}$ & $\begin{array}{l}\text { Kulit buah } \\
\text { dan kulit } \\
\text { batang }\end{array}$ & $\begin{array}{l}\text { Mengobati kanker, } \\
\text { penyakit jantung, } \\
\text { diare }\end{array}$ \\
\hline 18 & Crassulaceae & $\begin{array}{l}\text { Kalanchoe laciniata (L.) } \\
\text { DC }\end{array}$ & Sesejuk & Daun & Mengobati bisul \\
\hline 19 & Cucurbitaceae & Cucumis sativus L. & Boh timon & Buah & Darah tinggi \\
\hline
\end{tabular}




\begin{tabular}{|c|c|c|c|c|c|}
\hline No & Familia & Nama Ilmiah & Nama daerah & $\begin{array}{l}\text { Bagian } \\
\text { digunakan }\end{array}$ & Kegunaan \\
\hline & & $\begin{array}{l}\text { Zehneria ejecta F.M. } \\
\text { Bailey }\end{array}$ & $\begin{array}{l}\text { Boh timon } \\
\text { tikus }\end{array}$ & Buah & Darah tinggi \\
\hline & & $\begin{array}{l}\text { Sechium edule (Jacq.) } \\
\text { Sw. }\end{array}$ & Labu siam & $\begin{array}{l}\text { Buah dan } \\
\text { daun }\end{array}$ & $\begin{array}{l}\text { Kolesterol, tekanan } \\
\text { darah tinggi }\end{array}$ \\
\hline & & Momordica charantia L. & Pare & Buah & $\begin{array}{l}\text { Gangguan pencernaan, } \\
\text { penambah semangat }\end{array}$ \\
\hline \multirow[t]{2}{*}{20} & Euphorbiaceae & $\begin{array}{l}\text { Macaranga tanarius (L.) } \\
\text { Mull. Arg. }\end{array}$ & Seribu guna & Daun & $\begin{array}{l}\text { Kolesterol, diabetes, } \\
\text { jantung, sakit kepala, } \\
\text { lambung }\end{array}$ \\
\hline & & Jatropha curcas L. & On nawah & Daun & $\begin{array}{l}\text { Ramuan pasca } \\
\text { melahirkan, getah } \\
\text { untuk luka luar }\end{array}$ \\
\hline \multirow[t]{5}{*}{37} & Fabaceae & Abrus precatorius L. & Saga & Daun & Obat batuk, demam \\
\hline & & Tamarindus indica $\mathrm{L}$. & Boh me & $\begin{array}{l}\text { Buah dan } \\
\text { daun }\end{array}$ & $\begin{array}{l}\text { Pelangsing, campuran } \\
\text { ramuan obat pasca } \\
\text { melahirkan }\end{array}$ \\
\hline & & $\begin{array}{l}\text { Caesalpina pulcherrima } \\
\text { (L.) Sw. }\end{array}$ & On meurak & Daun & Batuk \\
\hline & & $\begin{array}{l}\text { Pterocarpus indicus } \\
\text { Willd. }\end{array}$ & Daun hasan & Daun & Demam \\
\hline & & Caesalpinia sappan L. & Kayu secang & Kulit kayu & Obat antidiabetes \\
\hline 38 & Gutiferrea & Mesua ferrea L. & Rancong buloh & Daun & $\begin{array}{l}\text { Campuran ramuan } \\
\text { pasca melahirkan, } \\
\text { batu karang }\end{array}$ \\
\hline \multirow[t]{3}{*}{39} & Lamiaceae & Ocimum tenuiflorum $\mathrm{L}$. & On reuhay & Daun & Sakit kepala \\
\hline & & $\begin{array}{l}\text { Orthosiphon aristatus } \\
\text { Benth. }\end{array}$ & Kumis kucing & Daun & Sakit pinggang \\
\hline & & $\begin{array}{l}\text { Plectranthus amboinicus } \\
\text { (Lour.) Spreng }\end{array}$ & Daun jinten & Daun & $\begin{array}{l}\text { Sesak nafas atau asma, } \\
\text { sakit kepala dan } \\
\text { pusing }\end{array}$ \\
\hline \multirow[t]{2}{*}{40} & Lauraceae & $\begin{array}{l}\text { Cinnamomum verum } \\
\text { J.Presl. }\end{array}$ & Kulet maneh & $\begin{array}{l}\text { Kulit } \\
\text { batang }\end{array}$ & Obat antidiabetes \\
\hline & & Persea americana Mill. & Boh pukat & Buah & Kolesterol \\
\hline 41 & Loranthaceae & Denthrophthoe sp. & Benalu kopi & $\begin{array}{l}\text { Semua } \\
\text { bagian }\end{array}$ & $\begin{array}{l}\text { Asam urat, koleterol, } \\
\text { jantung }\end{array}$ \\
\hline \multirow[t]{2}{*}{42} & Lythraceae & Punica granatum L. & Delima & $\begin{array}{l}\text { Daun dan } \\
\text { buah }\end{array}$ & Diare \\
\hline & & Lawsonia inermis L. & Inai & Daun & $\begin{array}{l}\text { Maag, campuran obat } \\
\text { melahirkan }\end{array}$ \\
\hline 43 & Apiaceae & $\begin{array}{l}\text { Centella asiatica (L.) } \\
\text { Urb. }\end{array}$ & On puegagan & Daun & $\begin{array}{l}\text { Penyembuh luka, obat } \\
\text { penenang alami, } \\
\text { kanker, awet muda }\end{array}$ \\
\hline \multirow[t]{2}{*}{44} & Malvaceae & Hibiscus sabdariffa L. & $\begin{array}{l}\text { Bungong } \\
\text { rosella }\end{array}$ & Bunga & Asam urat, hipertensi \\
\hline & & $\begin{array}{l}\text { Abelmoschus esculentus } \\
\text { (L.) Moench }\end{array}$ & Okra & Buah & $\begin{array}{l}\text { Diabetes, gangguan } \\
\text { pencernaan }\end{array}$ \\
\hline
\end{tabular}




\begin{tabular}{|c|c|c|c|c|c|}
\hline No & Familia & Nama Ilmiah & Nama daerah & $\begin{array}{l}\text { Bagian } \\
\text { digunakan }\end{array}$ & Kegunaan \\
\hline & & Hibiscus tiliaceus L. & Waru & Pucuk daun & $\begin{array}{l}\text { TBC, radang paru- } \\
\text { paru, muntah darah }\end{array}$ \\
\hline 45 & Meliaceae & Azadirachta indica Ness. & Bak syawardi & $\begin{array}{l}\text { Daun dan } \\
\text { kulit } \\
\text { batang }\end{array}$ & $\begin{array}{l}\text { Kanker serviks, } \\
\text { antimalaria, anti } \\
\text { jamur }\end{array}$ \\
\hline 46 & Moringaceae & Moringa oleifera Lam. & On murong & Daun & $\begin{array}{l}\text { Meningkatkan ASI, } \\
\text { kecacingan }\end{array}$ \\
\hline 47 & Multigiaceae & Muntingia calabura L. & On seri & $\begin{array}{l}\text { Buah dan } \\
\text { daun }\end{array}$ & Obat antidiabetes \\
\hline 48 & Myristicaceae & $\begin{array}{l}\text { Myristica fragrans } \\
\text { Houtt. }\end{array}$ & Pala & Biji & $\begin{array}{l}\text { Memar, campuran } \\
\text { obat pasca melahirkan }\end{array}$ \\
\hline \multirow[t]{2}{*}{49} & Myrtaceae & $\begin{array}{l}\text { Syzygium polyanthum } \\
\text { (Wight.) Walp. }\end{array}$ & On salam & $\begin{array}{l}\text { Daun, } \\
\text { cabang }\end{array}$ & $\begin{array}{l}\text { Kolesterol dan } \\
\text { diabetes, selain itu } \\
\text { juga digunakan untuk } \\
\text { pengharum masakan }\end{array}$ \\
\hline & & Psidium guajava L. & $\begin{array}{l}\text { Daun jambu } \\
\text { biji }\end{array}$ & $\begin{array}{l}\text { Daun dan } \\
\text { buah }\end{array}$ & $\begin{array}{l}\text { Diare, mencegah } \\
\text { kanker payudara }\end{array}$ \\
\hline 50 & Orchidaceae & $\begin{array}{l}\text { Anoectochilus setaceus } \\
\text { Blume }\end{array}$ & $\begin{array}{l}\text { Geurangsang } \\
\text { rimung }\end{array}$ & Daun & Penambah stamina \\
\hline \multirow[t]{2}{*}{51} & Oxalidaceae & Averrhoa bilimbi L. & Boh limeng & $\begin{array}{l}\text { Buah, daun } \\
\text { dan bunga }\end{array}$ & $\begin{array}{l}\text { Menurunkan tensi } \\
\text { darah, bunga } \\
\text { digunakan untuk } \\
\text { sariawan, daun } \\
\text { digunakan untuk obat } \\
\text { gatal dan campuran } \\
\text { ramuan pasca } \\
\text { melahirkan }\end{array}$ \\
\hline & & Averrhoa bilimbi L. & Belimbing sago & Buah & $\begin{array}{l}\text { Tekanan darah tinggi, } \\
\text { gangguan ginjal }\end{array}$ \\
\hline 52 & Parmaliacea & $\begin{array}{l}\text { Usnea barbata (L.) } \\
\text { Weber ex F.H. Wigg }\end{array}$ & $\begin{array}{l}\text { Akar simpul } \\
\text { angin }\end{array}$ & Akar & $\begin{array}{l}\text { Campuran ramuan } \\
\text { obat pasca melahirkan }\end{array}$ \\
\hline \multirow[t]{3}{*}{53} & Phyllanthaceae & $\begin{array}{l}\text { Phyllanthus pulcher } \\
\text { Wall. Ex. Mull.Arg. }\end{array}$ & On bangguri & Daun & Obat sakit kepala \\
\hline & & Phyllanthus urinaria L. & On me tanoh & Daun & $\begin{array}{l}\text { Sakit pinggang, obat } \\
\text { wasir, penyakit } \\
\text { kuning, disentri, } \\
\text { program hamil, } \\
\text { kencing batu. }\end{array}$ \\
\hline & & $\begin{array}{l}\text { Sauropus androgynus } \\
\text { (L.) Merr. }\end{array}$ & On katuk & Daun & $\begin{array}{l}\text { Menambah ASI pada } \\
\text { ibu melahirkan }\end{array}$ \\
\hline \multirow[t]{3}{*}{54} & Piperaceae & Piper nigrum L. & Lada & Biji & $\begin{array}{l}\text { Obat kanker, } \\
\text { campuran ramuan } 44\end{array}$ \\
\hline & & Piper betle L. & Ranub & Daun & $\begin{array}{l}\text { Keputihan, mata } \\
\text { bengkak, koleterol }\end{array}$ \\
\hline & & Piper crocatum L. & Ranub mirah & Daun & $\begin{array}{l}\text { Obat antidiabetes, } \\
\text { asam urat, keputihan, } \\
\text { kolesterol. }\end{array}$ \\
\hline
\end{tabular}




\begin{tabular}{|c|c|c|c|c|c|}
\hline No & Familia & Nama Ilmiah & Nama daerah & $\begin{array}{l}\text { Bagian } \\
\text { digunakan }\end{array}$ & Kegunaan \\
\hline \multirow{4}{*}{55} & \multirow{4}{*}{ Poaceae } & Piper nigrum L. & Lada hitam & Biji & $\begin{array}{l}\text { Obat kanker, } \\
\text { campuran ramuan } 44\end{array}$ \\
\hline & & Piper ornatum L. & Sirih merah & Daun & $\begin{array}{l}\text { Obat sakit mata, } \\
\text { campuran ramuan } \\
\text { pasca melahirkan, } \\
\text { antiseptik. }\end{array}$ \\
\hline & & $\begin{array}{l}\text { Andropogon nardus (L.) } \\
\text { Rendle }\end{array}$ & Sereh & $\begin{array}{l}\text { Akar dan } \\
\text { batang }\end{array}$ & $\begin{array}{l}\text { Diabetes tipe 2, } \\
\text { deman, nyeri, infeksi } \\
\text { dan rematik, bisa juga } \\
\text { digunakan sebagai } \\
\text { anti nyamuk dan } \\
\text { aroma terapi }\end{array}$ \\
\hline & & Imperata cylindrica $\mathrm{L}$. & Alang-alang & $\begin{array}{l}\text { Akar dan } \\
\text { batang }\end{array}$ & $\begin{array}{l}\text { Panas dalam, mimisan, } \\
\text { campuran ramuan } \\
\text { pasca melahirkan }\end{array}$ \\
\hline 56 & Polygalaceae & Polygala paniculata $\mathrm{L}$. & Akar suasa & Akar & $\begin{array}{l}\text { Meningkatkan } \\
\text { stamina }\end{array}$ \\
\hline \multirow[t]{3}{*}{57} & Rubiaceae & $\begin{array}{l}\text { Myrmecodia lamii Merr. } \\
\text { \& L.M. Perry }\end{array}$ & Sarang semut & Umbi & $\begin{array}{l}\text { Obat antidiabetes, } \\
\text { kolesterol }\end{array}$ \\
\hline & & Morinda citrifolia L. & Mengkudu & $\begin{array}{l}\text { Buah dan } \\
\text { daun }\end{array}$ & Obat darah tinggi \\
\hline & & Uncaria gambir Roxb. & Gambe & Daun & $\begin{array}{l}\text { Antidiabetes dan } \\
\text { kembung pada anak }\end{array}$ \\
\hline \multirow[t]{4}{*}{58} & Rutaceae & $\begin{array}{l}\text { Citrus aurantifolia } \\
\text { Swingle }\end{array}$ & Boh kuyeuen & $\begin{array}{l}\text { Buah dan } \\
\text { daun }\end{array}$ & $\begin{array}{l}\text { Obat batuk, campuran } \\
\text { untuk ramuan obat } \\
\text { melahirkan }\end{array}$ \\
\hline & & Citrus aurantium L. & Boh meuteu & Buah & Bahan tambahan \\
\hline & & Citrus histyx DC & Boh kruet & Buah & Bahan tambahan \\
\hline & & Citrus $s p$ & Boh maken & Buah & Bahan tambahan \\
\hline 59 & Salicaceae & Salix babylonica L. & On jaloh & Daun & $\begin{array}{l}\text { Demam, ramuan pasca } \\
\text { melahirkan, malaria }\end{array}$ \\
\hline 60 & Sapindaceae & $\begin{array}{l}\text { Erioglossum } \\
\text { rubiginosum (Roxb) }\end{array}$ & Boh kueulayu & Buah & Diare \\
\hline 61 & Sapotaceae & $\begin{array}{l}\text { Manilkara zapota (L.) } \\
\text { P.Royen }\end{array}$ & Sawo & Buah muda & $\begin{array}{l}\text { Diare dan panas } \\
\text { dalam }\end{array}$ \\
\hline 62 & Simaroubaceae & $\begin{array}{l}\text { Eurycoma longifolia } \\
\text { Jack. }\end{array}$ & On tungkat ali & $\begin{array}{l}\text { Daun, akar } \\
\text { dan kulit }\end{array}$ & $\begin{array}{l}\text { Penambah stamina } \\
\text { pasca lahir, ejakulasi } \\
\text { dini dan obat pria }\end{array}$ \\
\hline \multirow[t]{2}{*}{63} & Solanaceae & Physalis angulata $\mathrm{L}$. & Ciplukan & Daun & $\begin{array}{l}\text { Stroke, diabetes, } \\
\text { kolesterol, }\end{array}$ \\
\hline & & Solanum torvum Sw. & Trung cawing & Buah & Obat mata \\
\hline 64 & Thymelaeaceae & $\begin{array}{l}\text { Phaleria macrocarpa } \\
\text { (Scheff.) Boerl. }\end{array}$ & Mahkotadewa & Kulit buah & Jantung, koleterol \\
\hline 65 & Verbenaceae & $\begin{array}{l}\text { Stachytarpheta } \\
\text { jamaicensis (L.) Vahl. }\end{array}$ & On seuriba & Daun & Lebam atau memar \\
\hline
\end{tabular}




\begin{tabular}{|c|c|c|c|c|c|}
\hline No & Familia & Nama Ilmiah & Nama daerah & $\begin{array}{l}\text { Bagian } \\
\text { digunakan }\end{array}$ & Kegunaan \\
\hline \multirow[t]{15}{*}{67} & Zingiberaceae & Curcuma pallida Lour & $\begin{array}{l}\text { Kunyet } \\
\text { kusumbu }\end{array}$ & Rimpang & Maag dan lambung \\
\hline & & $\begin{array}{l}\text { Curcuma zanthorrhiza } \\
\text { Roxb. }\end{array}$ & Temulawak & Rimpang & $\begin{array}{l}\text { Penambah nafsu } \\
\text { makan, penambah ASI }\end{array}$ \\
\hline & & Zingiber sp & Halia merah & Rimpang & $\begin{array}{l}\text { Masuk angin, obat } \\
\text { patah tulang }\end{array}$ \\
\hline & & Zingiber officinale Roxb. & Halia & Rimpang & Masuk angin \\
\hline & & Alpina galanga & Boh rangkueh & Rimpang & Panu, obat rematik \\
\hline & & Kaempferia galanga & Boh cuko & Rimpang & Obat sakit kepala \\
\hline & & Curcuma longa & Kunyet & Rimpang & $\begin{array}{l}\text { maag, campuran obat } \\
\text { pasca melahirkan, } \\
\text { mengobati luka }\end{array}$ \\
\hline & & $\begin{array}{l}\text { Zingiber cassumunar } \\
\text { Robx }\end{array}$ & Kunyet molay & Rimpang & $\begin{array}{l}\text { Ramuan obat pasca } \\
\text { melahirkan }\end{array}$ \\
\hline & - & Sp.1 & Sanamaki & Daun & $\begin{array}{l}\text { Campuran ramuan } \\
\text { obat pasca melahirkan }\end{array}$ \\
\hline & - & Sp.2 & On urat lhee & Daun & $\begin{array}{l}\text { Campuran obat } \\
\text { kolesterol }\end{array}$ \\
\hline & - & Sp.3 & On suerapat & Daun & $\begin{array}{l}\text { Campuran ramuan } \\
\text { obat pasca melahirkan }\end{array}$ \\
\hline & - & Sp.4 & On sikuat & Daun & Asam urat \\
\hline & - & Sp.5 & On iku manok & Daun & Awsir, disentri \\
\hline & - & Sp.6 & On tin & Daun & Paru-paru \\
\hline & - & Sp.7 & $\begin{array}{l}\text { On gajah } \\
\text { tunggai }\end{array}$ & Daun & Rematik, asam urat \\
\hline
\end{tabular}

\section{UCAPAN TERIMA KASIH}

Peneliti mengucapakan terimakasih banyak kepada Kementerian Riset, Teknologi dan Perguruan Tinggi (Kemenristekdikti) atas bantuan dan dana hibah Penelitian Dosen Pemula (PDP) dan Universitas Serambi Mekkah serta LPPM USM yang memfasilitasi penelitian ini.

\section{DAFTAR PUSTAKA}

Asep, A. A., E. Noviani, R. Partasasmita \& J. Iskandar. (2016). Studi Etnobotani Pemanfaatan Jenis-jenis Tumbuhan yang digunakan Sebagai Obat oleh Masyarakat Desa Pangandaran, Kecamatan Pangandaran, Kabupaten Pangandaran. Prosiding Seminar Nasional MIPA, 26-28 Oktober 2016. Universitas Padjajaran.

Astutik, S., Pretezsch, J., Kimengsi, J,N. (2019). Asian Medicinal Plants Production and Utilization Potentials: A Review. Sustainability, 11:17.

Efremila., E. Wardenaar., L. Sisilia. (2015). Studi Etnobotani Tumbuhan Obat Oleh Etnis Suku Dayak di Desa Kayu Tanam Kecamatan Mandor Kabupaten Landak. Jurnal Hutan Lestari. 3 (2): 234-246.

Febrisari, A., Valeria, F., Chandra, N.S., Fitrah, S.F.K., Palupi, D.Y., (2008). Pendayagunaan Tumbuhan Liar Alang-alang (Imperata cylindrica) Sebagai Softdrink Hernal Dalam Rangka Optimalisasi Lingkungan, IPB, Bogor.

Kuntorini, E.K. 2005. Botani Ekonomi Suku Zingiberaceae Sebagai Obat Tradisional oleh Masyarakat di Kotamadya Banjarbaru. Bioscientiae. 2 (1):25-36. 
Limananti, A. I., T. Atik. 2003. Ramuan Jamu Cekok Sebagai Penyembuh Kurang Nafsu Makan pada Anak: Suatu Kajian Etnomedisin. Jurnal Makara Kesehatan. 7 (10): 11-20.

Ma'mun. 2006. Karakteristik Beberapa Minyak Atsiri Famili Zingiberaceae dalam Perdagangan. Bul. Litro. XVII (2): 91-98.

Mabel, Y., H. Simbala., R. Koneri. 2016. Identifikasi dan Pemanfaatan Tumbuhan Obat Suku Dani di Kabupaten Jayawijaya, Papua. Jurnal MIPA Unsrat Online. 5 (1): 103-107.

Murni. S. A., P. Prawito., S. Widiono. 2012. Eksistensi Pemanfaatan Tanaman Obat Tradisional (TOT) Suku Serawai Diera Medikalisasi Kehidupan. Jurnal Penelitian Pengelolaan Sumber Daya Alam dan Lingkungan, 1(3):225-233.

Nasution, J. 2009. Oukup, Ramuan Tradisional Suku Karo Untuk Kesehatan Pasca Melahirkan: Suatu Analisa Bioprospeksi Tumbuh-tumbuhan Tropika Indonesia. Tesis. Institut Pertanian Bogor.

Noorhidayah, Kade Sidiyasa, Ibnu Hajar, 2006. Potensi dan keragaman tumbuhan obat di hutan Kalimantan dan upaya konservasinya, Jurnal Analisis Kebijakan Kehutanan Kehutanan, 3(2): 96-107.

Praptiwi, T., Jamal, Y., Wulansari, D., Fathoni,A., Palupi, K.D., Agusta, A., (2015). Skrining Aktivitas Antioksidan Beberapa Tumbuhan Suku Zingiberaceae. Prosiding Seminar Biodiversitas, 4: 3.

Pramesti, G., F. Arum., A. Retnoningsih, A. Irsadi. 2012. Etnobotani Tumbuhan Obat Masyarakat Desa Keseneg Kecamatan Sumowono Kabupaten Semarang Jawa Tengah. Unnes Journal of Life Science, 1(2): 12-132.

Sampurno. 2007. Obat Herbal Dalam Perspektif Medik dan Bisnis. Journal Traditional Medicine, 12(42): $18-27$.

Susiati, S. 2015. Pengetahuan dan Pemanfataan Tumbuhan Obat Masyarakat Lokal di Pulau Seram, Maluku. Prosiding Seminar Nasional Masyarakat Biodiversitas Indonesia, 1(5): 1083-1087.

Wardiah., Hasanuddin., Mutmainnah. 2015. Etnobotani Medis Masyarakat Kemukiman Pulo Breueh Selatan Kecamatan Pulo Aceh Kabupaten Aceh Besar. Jurnal Edubio Tropika. 3(1):1-50.

Widiyastuti, Y., Adi, M.B.S., Widayat, T., 2018. Spesies Tumbuhan Obat di Cagar Alam Sigogor Ponorogo Jawa Timur, Jurnal Tumbuhan Obat Indonesia, 10 (2): 78-97 